\title{
Long-term result of direct frontalis sling with fascia lata in congenital ptosis
}

\author{
Nam Yeong Kim, MD, Hee Bae Ahn, MD, PhD \\ Department of Ophthalmology, Dong-A University College of Medicine, Busan, Rep. of Korea
}

\begin{abstract}
Background: Congenital ptosis with poor levator function are very difficult to make good results of functional and cosmetic side. Surgical methods for the correction of congenital ptosis with poor levator function, including frontalis suspension or maximal levator resection, remain controversial. We evaluated the postoperative surgical and cosmetic long-term outcomes after frontalis sling operation with preserved fascia lata for congenital ptosis with poor levator function.

Objective: To evaluate the long-term outcome of asymmetric ptosis with frontalis sling operation preserved fascia lata by modified direct tarsal fixation in congenital ptosis patients.

Methods: A retrospective case series was performed. From January 2000 to December 2018, 53 patients (30 unilateral and 23 bilateral asymmetric ptosis) with 70 eyelids who underwent frontalis sling with preserved fascia lata were included. Six patients underwent levator resection at opposite eye. The surgical results were graded as excellent, good and poor.

Results: The mean age at the time of surgery was $5.2 \pm 3.2$ years (range, 1-43 years) with a mean follow-up time of 106.6 \pm 29.1 months (range, 60-196 months). Satisfactory results (excellent or good result) were obtained in $94.2 \%$ of the patients. Patients were divided into two groups based on levator function as follows: 0 to $2 \mathrm{~mm}$ (24 cases) and 2.5 to $4.0 \mathrm{~mm}$ (46 cases). Preoperative levator function, margin reflex distance-1 and levator dehiscence were not correlated with postoperative surgical outcomes. Complications were exposure keratopathy (8.6\%), lidcrease asymmetry (7.1\%), overcorrection (5.7\%), entropion (5.7\%), and eyelash ptosis (2.9\%). Conclusion: Frontalis sling operation by preserved fascia lata with modified direct tarsal fixation is a simple but effective treatment for severe congenital ptosis with poor levator function. And it has good long-term results.
\end{abstract}

Keywords: congenital ptosis; frontalis sling; ptosis

\section{Introduction}

Congenital ptosis can cause several negative effects when left untreated. Unilateral congenital ptosis could lead to deprivation amblyopia, while bilateral congenital ptosis may cause abnormal head posturing. The most common etiopathogenesis of congenital ptosis is levator muscle dystrophy, wherein the muscle and aponeurotic tissues are often infiltrated and/or replaced by adipose tissue or fibrous tissue. In patients with con- genital ptosis, levator function and severity of ptosis determine the selection of surgical technique [1]. Frontalis sling surgery is the first-line treatment for congenital ptosis with poor levator function [2-4]. Autogenous fascia lata is the gold standard for this operation. However, it requires a second incision and cannot be used in very young children [5]. Allograft fascia lata may be an ideal substitute [6].

There are several surgical techniques for frontalis sling surgery including pentagonal pattern, double rhomboid pattern, 
triangular pattern, and modified double triangular pattern [711]. A simple yet effective surgical technique is the direct tarsal and frontalis fixation, invented by Spoor and Kwitko [12] in 1990. With direct fixation, it is easier to create a lid crease and adjust the lid contour.

Here, we describe the long-term clinical results of modified direct frontalis sling operation with preserved fascia lata in patients with unilateral congenital ptosis and bilateral congenital ptosis.

\section{Materials and methods}

We conducted a retrospective case study of patients who were diagnosed with congenital ptosis with poor levator function. The patients underwent modified direct tarsal fixation using preserved fascia lata performed by a single surgeon (HB Ahn) from January 2000 to December 2014, in Dong-A University Hospital in Busan, Korea.

Patients with blepharophimosis syndrome, Marcus-Gunn jaw-winking synkynesis, neurogenic, traumatic ptosis, and inadequate data including postoperative follow-up less than 5 years in duration were excluded. Data collected included age, sex, history of prior surgery, comorbidity, preoperative and postoperative digital or Polaroid photographs, ptosis assessment including pre-postoperative margin reflex distance-1 (MRD1), levator function, postsurgical results, and related complications. Measurements of preoperative and postoperative MRD1 were performed using ImageJ software (National Institutes of Health, Bethesda, MD, USA) by 2 blinded observers.

All surgeries were performed under general anesthesia by one surgeon (HB Ahn) assisted by a resident or fellow. All patients were evaluated postoperatively by the same surgeon. A lid crease line was designed and drawn with a marking pen above the lash line. Two stab incision sites were marked just above the eyebrow. The upper eyelid and suprabrow tissue were infiltrated with a mixture of lidocaine $2 \%$ and 1:100,000 epinephrine. The lid skin was incised at the lid crease, and dissection was propagated through the orbicularis muscle to expose some of the tarsal plate. Two pieces of Tutoplast (Biodynamics International, Erlangen, Germany), a commercially available processed fascia lata allograft, were prepared. The ends of the 2 pieces of fascia lata were anchored to the upper tarsus with 6-0 nylon (Ethicon Inc., Somerville, NJ, USA) suture. Both ends of the anchoring suture were left uncut. A pair of Kelly forceps was inserted into the suprabrow incision, through the tissues and out through the lower lid crease. Subsequently, Kelly forceps were used to grasp the free end of the sutured fascia lata and pull it through the side of the suprabrow incision. The same procedure was performed on the remaining fascia lata. The orbital septum was penetrated at the arcus marginalis, creating a passage directed toward the eyelid. After adjusting the proper lid height, the remaining ends of the fascia lata were cut off. The ends were eventually fixed and buried in the suprabrow incision with 6-0 nylon (Ethicon Inc.) suture. With the sutures left uncut, an eyelid fold was formed by fixing the skin incision to the tarsus. The lid crease was sutured using the continuous technique, and the suprabrow incisions were closed using the vertical mattress technique with 6-0 plain gut sutures (Fig. 1).

The surgical outcomes were categorized as good, fair, or poor based on the postoperative MRD1 (Table 1). We defined overcorrection as $1 \mathrm{~mm}$ higher than the opposite lid with an eyelid that did not cover the limbus. We also compared the eyelid measurements and surgical outcomes according to levator function. Patients were further divided into 2 groups depending on the severity of levator function as $\leq 2 \mathrm{~mm}$ and $\geq 2.5 \mathrm{~mm}$. Statistical analysis was performed using PASW Statistics software
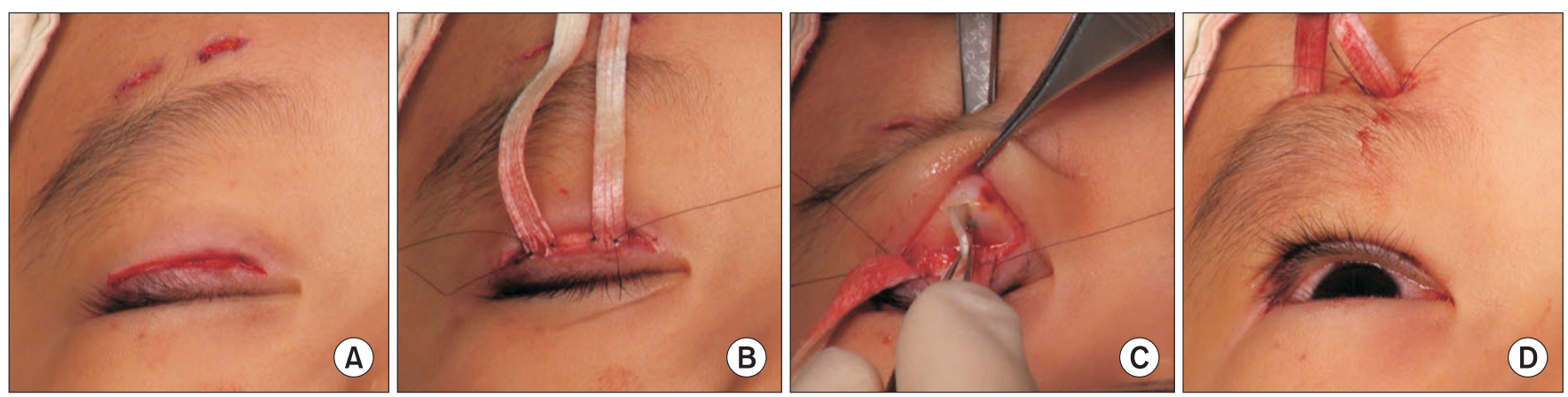

Fig. 1. (A) Incision was performed at lid crease and suprabrow. (B) The ends of the two pieces of fascia lata were anchored to the upper tarsus with 6-0 nylon suture. (C) A Kelly was inserted into the suprabrow incision, grabbing the free end of the sutured fascia lata. (D) The fascia lata was sutured at suprabow incisions with proper lid position. 
Table 1. Categorization of surgical outcome

\begin{tabular}{clc}
\hline Surgical outcome & Unilateral ptosis & Bilateral asymmetric ptosis \\
\hline Good & MRD1 is $\leq 1 \mathrm{~mm}$ compared with the opposite eye & $\begin{array}{c}\text { MRD1 is } \geq 2 \mathrm{~mm} \text { in each eye and MRD1 is } \leq 1 \mathrm{~mm} \text { compared } \\
\text { with the opposite eye } \\
\text { Fair }\end{array}$ \\
MRD1 is $\leq 2 \mathrm{~mm}$ lower than the opposite eye & $\begin{array}{c}\text { MRD1 is } \geq 1 \mathrm{~mm} \text { or }<2 \mathrm{~mm} \text { and MRD1 is } \leq 2 \mathrm{~mm} \text { lower than } \\
\text { the opposite eye }\end{array}$ \\
Poor & $\begin{array}{c}\text { MRD1 is }>1 \mathrm{~mm} \text { (overcorrection) or }<2 \mathrm{~mm} \text { compared } \\
\text { with the opposite eye }\end{array}$ & $\begin{array}{c}\text { MRD1 is }<1 \mathrm{~mm} \text { or }>1 \mathrm{~mm} \text { (overcorrection) or MRD1 is } \\
>2 \mathrm{~mm} \text { lower than the opposite eye }\end{array}$ \\
\hline
\end{tabular}

MRD1, marginal reflex distance-1.

Table 2. Demographic characteristics of 53 patients who underwent direct frontalis sling fixation

\begin{tabular}{|c|c|c|c|c|}
\hline Characteristic & Unilateral & Bilateral & Total & p-value \\
\hline No. of patients & 30 & 23 & 53 & \\
\hline \multicolumn{5}{|l|}{ Age at operation (yr) } \\
\hline Mean \pm SD & $5.3 \pm 5.8$ & $4.9 \pm 1.9$ & $5.2 \pm 3.2$ & $0.57^{*}$ \\
\hline Range & $1-43$ & $1-23$ & $1-43$ & \\
\hline Sex & & & & $0.49^{\dagger}$ \\
\hline Female & 13 & 8 & 21 & \\
\hline Male & 17 & 15 & 32 & \\
\hline Preoperative LF (mm) & $2.9 \pm 0.8$ & $3.1 \pm 1.0$ & $3.0 \pm 0.9$ & $0.20^{*}$ \\
\hline Preoperative MRD1 (mm) & $-0.4 \pm 0.8$ & $0.0 \pm 0.9$ & $-0.4 \pm 0.8$ & $0.15^{*}$ \\
\hline Range & -3 to +2 & -1 to +2 & -3 to +2 & \\
\hline Follow-up duration (mo) & & & & $0.16^{*}$ \\
\hline Mean \pm SD & $104 \pm 30.4$ & $110.5 \pm 28.7$ & $106.6 \pm 29.1$ & \\
\hline Range & 60-196 & $60-127$ & $60-196$ & \\
\hline
\end{tabular}

Values are presented as number only, mean $\pm \mathrm{SD}$, or range.

LF, levator function; MRD1, marginal reflex distance-1.

*Independent t-test; ${ }^{\dagger}$ Chi-squared test.

ver. 18.0 (IBM Corp., Armonk, NY, USA). Paired t-tests were employed to analyze demographic data and eyelid measurements to compare the unilateral and asymmetric bilateral ptosis groups. Statistical significance was defined as $\mathrm{p}<0.04$.

\section{Results}

A total of 70 eyelids on 53 patients were included in the study. There were 30 patients who had unilateral ptosis and 23 patients who had bilateral asymmetric ptosis. Of the 23 patients, 6 underwent levator resection on the opposite eye. The demographic characteristics of the patients are summarized in Table 2 . There were 32 male patients and 21 female patients. The mean age at the time of surgery was 5.2 \pm 3.2 years (range, 1-43 years) with a mean follow-up time of $106.6 \pm 29.1$ months (range, 60-196 months). There was no statistical difference in demographics between the unilateral and bilateral asymmetric ptosis groups. The preoperative levator function was $2.9 \pm 0.8 \mathrm{~mm}$ in the unilateral ptosis group and $3.1 \pm 1.0 \mathrm{~mm}$ in the bilateral asymmetrical ptosis group. The difference was not statistically
Table 3. Surgical outcomes of direct frontalis sling fixation*

\begin{tabular}{lccc}
\multicolumn{1}{c}{ Variable } & Unilateral & Bilateral & Total \\
\hline No. of eyes & 30 & 40 & 70 \\
Surgical outcome & & & \\
Good & $18(60.0)$ & $25(62.5)$ & $43(61.4)$ \\
Fair & $8(26.7)$ & $11(27.5)$ & $19(27.1)$ \\
Poor & $4(13.3)$ & $4(10.0)$ & $8(11.4)$ \\
\hline
\end{tabular}

Values are presented as number only or number (\%).

${ }^{*} \mathrm{p}=0.25$ by chi-squared test.

significant $(\mathrm{p}=0.20)$. The preoperative MRD1 was $-0.4 \pm 0.8 \mathrm{~mm}$ (range, -3 to $+2 \mathrm{~mm}$ ).

On the classification of surgical outcomes, satisfactory results or good was obtained in 43 eyes (61.4\%), fair in 19 eyes (27.1\%), and poor in 8 eyes (11.4\%) on their last follow-up (Table 3). In the unilateral ptosis group, 18 eyes $(60.0 \%)$ had good results, 8 eyes $(26.7 \%)$ had fair results, and 4 eyes $(13.3 \%)$ had poor results. In the bilateral asymmetric ptosis group, good results were obtained in 25 eyes (62.5\%), good in 11 eyes (27.5\%), and poor in 4 eyes (10.0\%). The surgical outcomes were not statistically different between the two groups $(\mathrm{p}=0.25)$. 
Table 4. Success rate according to levator function (LF)

\begin{tabular}{lccc}
\hline \multicolumn{1}{c}{ Variable } & LF 0-2 $\mathbf{~ m m}$ & LF 2.5-4 $\mathbf{~ m m}$ & p-value \\
\hline No. of eye & 24 & 46 & $0.45^{*}$ \\
\hline Age at operation (yr) & $5.1 \pm 4.6$ & & \\
\hline Preoperative eyelid measurement $(\mathrm{mm})$ & & $3.3 \pm 0.5$ & $0.001^{*}$ \\
\hline LF & $1.3 \pm 0.4$ & $0.5 \pm 0.9$ & $0.001^{*}$ \\
\hline MRD1 & $-0.4 \pm 1.1$ & & $0.23^{\dagger}$ \\
\hline Surgical result & & $28(60.9)$ & $13(28.3)$ \\
\hline Good & $15(62.5)$ & $5(10.9)$ & \\
\hline Fair & $6(25.0)$ & & \\
\hline Poor & $3(12.5)$ & & \\
\hline
\end{tabular}

Values are presented as number only, mean \pm SD, or number (\%).

MRD1, marginal reflex distance-1.

*Mann-Whitney test; ${ }^{\dagger}$ Fisher's exact test.

Patients were divided into two groups based on levator function as follows: $0-2 \mathrm{~mm}$ (24 eyes) and $2.5-4.0 \mathrm{~mm}$ (46 eyes). Comparisons of the 2 groups according to levator muscle function are shown in Table 4. There was no significant difference in postoperative surgical results between the 2 groups ( $\mathrm{p}=0.23$ ). The complications were exposure keratopathy ( 6 eyes, $8.6 \%$ ), lid crease asymmetry (5 eyes, 7.1\%), overcorrection ( 4 eyes, $5.7 \%$ ), entropion ( 4 eyes, $5.7 \%$ ), and eyelash ptosis ( 2 eyes, $2.9 \%$ ).

\section{Discussion}

The surgical procedure of choice in congenital ptosis depends on several factors. When deciding on surgery, the main criteria should be the degree of ptosis and levator function. The treatment of choice for moderate to severe congenital ptosis with minimal or no levator function is frontalis sling operation [2-4]. When performing a frontalis sling operation, a surgeon must select both the surgical method and the sling material. There are several established surgical methods [5-11], but the open sky method [13] and the modified Crawford method [14] are currently 2 of the most popular choices for oculoplastic surgeons. Suspensory materials for the frontalis sling operation can be divided into 3 categories, namely, synthetic, autogenous fascia lata, and allograft fascia lata. Autograft fascia lata is generally considered the best material $[7,14-17]$ because it does not degrade and is believed to allow fibrovascular tissue ingrowth leading to biointegration without significant inflammation. Additionally, there is less chance of infection associated with the sling. Autograft fascia lata has good long-term results with maintenance of lid height $[7,14,15]$. However, Crawford $[7,14]$ recommended using it only in children older than 3 years because there is difficulty in harvesting this material when the leg is too short, thereby obtaining an insufficient amount of fascia lata. Furthermore, the process requires a long operation time and results in postoperative leg scarring. For these reasons, the use of allograft fascia lata as an alternative material has been promoted. Allograft fascia carries some risk of potential infection because it is a synthetic material. However, it avoids the need for a second surgical site. There have been several reports on the outcome of frontalis sling operation with allograft, namely, preserved fascia lata. Many of them reported a higher rate of late ptosis recurrence than that of frontalis sling operation with autograft [6,16-19].

Our direct tarsal fixation technique was invented by Spoor and Kwitko [12] in 1990 and is superior with regard to adjustment of eyelid height and in ensuring firm anchoring of the sling material. However, the method in our study was somewhat different [20]. We made the procedure simpler and more effortless. We believe this modified method is better than the original technique because it requires smaller incisions, thus leaving smaller scars. Consequently, there is minimal trauma to the adjacent tissues and incorporation, and biointegration is improved. This can decrease postoperative complications and recurrence. The preserved fascia lata used in the operation showed a good safety profile with no infection or exposure over the follow-up period.

Our study had a relatively long follow-up period, with few complications and recurrence. The limitations of the study are that it was a single-center study, had a retrospective design, and did not have a control group using autogenous fascia lata or another sling method.

In conclusion, the results are quite encouraging. We believe our study supports the long-term stability of the procedure. Therefore, we conclude that frontalis sling operation with modified direct tarsal fixation by preserved fascia lata is a relatively simple but effective procedure showing a good long-term result 
and should be considered as a good surgical solution for severe congenital ptosis.

\section{Conflicts of interest}

The authors have nothing to disclose.

\section{References}

1. Bilgin LK, Yeniad B. The long-term results of frontalis suspension using autogenous fascia lata in children with congenital ptosis under 3 years old. Plast Surg Int 2010;2010:609462.

2. Fox SA. Congenital ptosis II. Frontalis sling. J Paediatr Ophthalmol 1966;3:25-8.

3. Beard C. Ptosis. 3rd ed. St. Louis, MO: Mosby; 1981.

4. Mustarde JC. Repair and reconstruction in the orbital region. 2nd ed. Edinburgh: Churchill Livingstone; 1980.

5. Ben Simon GJ, Macedo AA, Schwarcz RM, Wang DY, McCann JD, Goldberg RA. Frontalis suspension for upper eyelid ptosis: evaluation of different surgical designs and suture material. Am J Ophthalmol 2005;140:877-85.

6. Wilson ME, Johnson RW. Congenital ptosis. Long-term results of treatment using lyophilized fascia lata for frontalis suspensions. Ophthalmology 1991;98:1234-7.

7. Crawford JS. Repair of ptosis using frontalis muscle and fascia lata. Trans Am Acad Ophthalmol Otolaryngol 1956;60:672-8.

8. Fox SA. A new frontalis skin sling for ptosis. Am J Ophthalmol 1968;65:359-62.

9. Goldberger S, Conn H, Lemor M. Double rhomboid silicone rod frontalis suspension. Ophthalmic Plast Reconstr Surg 1991;7:48-53.

10. Mauriello JA Jr, Abdelsalam A. Effectiveness of homologous cadaveric fascia lata and role of suture fixation to tarsus in frontalis suspension. Ophthalmic Plast Reconstr Surg 1998;14:99-104.

11. Seider N, Beiran I, Kaltreider SA. One medial triangular Tutoplast sling as a frontalis suspension for adult myogenic blepharoptosis. Acta Ophthalmol Scand 2006;84:121-3.

12. Spoor TC, Kwitko GM. Blepharoptosis repair by fascia lata suspension with direct tarsal and frontalis fixation. Am J Ophthalmol 1990;109:314-7.

13. Morax S, Benia L. [Suspension of the eyelid to the frontal muscle in the surgery of ptosis. Technic and indications]. J Fr Ophtalmol 1986;9:461-70. French.

14. Crawford JS. Frontalis sling operation. J Pediatr Ophthalmol Strabismus 1982;19:253-5.

15. Crawford JS. Repair of ptosis using frontalis muscle and fascia lata: a 20-year review. Ophthalmic Surg 1977;8:31-40.

16. Wagner RS, Mauriello JA Jr, Nelson LB, Calhoun JH, Flanagan JC, Harley RD. Treatment of congenital ptosis with frontalis suspension: a comparison of suspensory materials. Ophthalmology 1984;91:245-8.

17. Wasserman BN, Sprunger DT, Helveston EM. Comparison of materials used in frontalis suspension. Arch Ophthalmol 2001;119:687-91.

18. Beyer CK, Albert DM. The use and fate of fascia lata and sclera in ophthalmic plastic and reconstructive surgery. Ophthalmology 1981;88:869-86.

19. Broughton WL, Matthews JG 2nd, Harris DJ Jr. Congenital ptosis. Results of treatment using lyophilized fascia lata for frontalis suspensions. Ophthalmology 1982;89:1261-6.

20. Suh JY, Ahn HB. Ptosis repair using preserved fascia lata with the modified direct tarsal fixation technique. Korean J Ophthalmol 2013;27:311-5. 